\title{
Hydrogen adsorption of nitrogen-doped carbon nanotubes functionalized with 3d-block transition metals
}

\author{
MICHAEL R MANANGHAYA \\ De La Salle University-Manila, Taft Ave., Manila 1004, Philippines \\ e-mail: mikemananghaya@gmail.com
}

MS received 14 May 2014; revised 9 October 2014; accepted 24 November 2014

\begin{abstract}
A systematic study of the most stable configurations, calculation of the corresponding binding and free energies of functionalized $3 \mathrm{~d}$ transition metals (TMs) on $(10,0)$ Single Walled Carbon Nanotube (SWCNT) doped with porphyrin-like nitrogen defects $\left(4 \mathrm{ND}-\mathrm{CN}_{\mathrm{x}} \mathrm{NT}\right)$ using spin-polarized density functional theory (DFT) formalism with flavours of LDA and GGA exchange-correlation (XC) functionals has been made. A thorough analysis showed that the electronic and magnetic properties of SWCNT are dependent on the TMs absorbed wherein, the composite material TM/4ND- $\mathrm{CN}_{\mathrm{x}} \mathrm{NT}$ can act as a medium for storing hydrogen at room temperature manifested through favourable adsorption energy.
\end{abstract}

Keywords. Binding energy; density functional theory; porphyrin defects; transition metals

\section{Introduction}

Introduction of defects and dopants can alter the electronic and magnetic properties of Single walled Carbon Nanotubes (SWCNT). Recently, efficient ways to modify the properties of carbon nanotubes (CNT) have attracted various groups of considerable interest. ${ }^{1-6}$ $\mathrm{B}$ and/or $\mathrm{N}$ have roughly the same atomic radius as $\mathrm{C}$ atoms. Specifically, $\mathrm{N}$ is a good choice of dopant that is expected to make semiconducting CNT metallic due to its one extra electron compared to a $\mathrm{C}$ atom. ${ }^{1-5}$ The N-doped CNT $\left(\mathrm{CN}_{\mathrm{x}} \mathrm{NT}\right)$ has been synthesized in several groups $^{7-12}$ using various approaches including magnetron sputtering, ${ }^{13}$ pyrolysis of nitrogen-rich organic chemicals, ${ }^{14}$ and arc-discharge in nitrogen atmosphere. ${ }^{15}$ However, most of the syntheses yield nitrogen-doped multi-walled carbon nanotubes $\left(\mathrm{MWCN}_{\mathrm{x}} \mathrm{NT}\right)$ with bamboo-shaped morphology. Recently, the synthesis of nitrogen-doped SWCNT bundles via an aerosol-assisted chemical vapour deposition (CVD) method was reported. ${ }^{16}$ It has been suggested that the nitrogen dopants are substituted into the carbon network with and without vacancy formation identified by electron energy loss spectroscopy and X-ray photoelectron spectroscopy measurements. ${ }^{9,10}$ Vacancy structures co-exist both as pyridine-like and porphyrin-like wherein the porphyrin-like nitrogen substitution accompanied with vacancy (4ND) formed in the sidewall of SWCNT is a four-nitrogen divacancy. The electronic, ${ }^{17}$ field emission ${ }^{18}$ and electrical transport properties ${ }^{19}$ of these structures have been investigated systemically. The presence of 4ND defects in CNT, suggests that the reactivity might be greatly enhanced compared to the pure CNT. ${ }^{16,20-28}$ The introduction of new levels close to the Fermi level with nitrogen doping can change the sensibility of CNT to different kinds of molecules. ${ }^{16,20,21}$ Modification of the electronic and magnetic properties of CNT can also typically be effectively modified through chemical decoration of transition metals (TMs), ${ }^{29-31}$ which greatly expands the potential application areas of CNT, such as improving the sensitivities of chemical sensors, developing spintronic devices or catalysts and providing higher reactive sites for hydrogen gas storages. ${ }^{24-28,32-37}$ 4ND defects in nitrogen-doped nanostructures may enhance reactivity and immobilize species such as transition metals, ${ }^{29-31}$ also the binding strengths of TMs with SWCNT doped with porphyrinlike nitrogen defects (4ND-CN $\left.{ }_{x} \mathrm{NT}\right)$ are significantly enhanced when compared to the pure SWCNT such that binding is stable and favourable dictated by a strong binding energy that could improve transition metal dispersion over the metal decorated SWCNT. Theoretical calculations revealed that the 4ND defects in SWCNT resulted in a decreased value of band gaps and the electronic properties of SWCNT can be effectively modified, which are strongly dependent on the TMs absorbed. ${ }^{38-43}$

The incorporation of nitrogen and transition metal atoms into carbon nanotubes affords structures with the ability to participate in hydrogen bonding. TMdispersed materials have been studied recently for large 
hydrogen storing capacity with respect to the release temperature, the TM- $\mathrm{H}_{2}$ binding energy and ratio which look very promising. ${ }^{32-37}$ US Department of Energy (DOE) Hydrogen Plan has set a standard for this discussion by providing a commercially significant benchmark for the amount of reversible hydrogen adsorption. The benchmark for the ratio of stored hydrogen weight to system weight requires an efficiency of $6.5 \mathrm{wt} \%$ hydrogen and a volumetric density of $62 \mathrm{~kg} \mathrm{H}_{2} / \mathrm{m}^{3}$. A systematic study of the most stable configurations, calculation of the corresponding binding and free energies of functionalized $3 \mathrm{~d}$ TMs on $(10,0)$ $4 \mathrm{ND}-\mathrm{CN}_{\mathrm{x}} \mathrm{NT}$ using DFT formalism is presented in the paper to show that the composite material TM/4ND$\mathrm{CN}_{\mathrm{X}} \mathrm{NT}$ can act as a medium for storing hydrogen at room temperature.

\section{Computational}

Calculations were performed on supercells of zigzag $(10,0)$ CNT with 4ND that is chemically functionalized with 10 different TMs (figure 1) using first-principles density functional theory (DFT), $\mathrm{Dmol}^{3}$ code, available from Accelrys. ${ }^{44}$ Experimentally produced CNTs have an average diameter of around $1 \mathrm{~nm}$. Theoretically, calculated diameter close to $1 \mathrm{~nm}$ can be considered; obviously dictated by the need to drastically reduce the computational effort in such a large unit cell, single-walled $(10,0)$ zigzag nanotube was chosen motivated by the small periodicity of the zigzag nanotubes compared to chiral ones. Thus the system is correspondingly small, which should justify the choice, as seen later on the discussion of the results. Each electronic wave function is expanded in a localized atom-centred basis set with each basis function defined numerically on a dense radial grid. For supercell geometries, spin-unrestricted calculations were carried out with a double numeric polarized (DNP) basis set available and the atomic cut-off set at $4.6 \AA$, along with gradient-corrected Perdew-BurkeErnzerhof (PBE/GGA) functional. ${ }^{45}$ Scalar relativistic effects were included via a local pseudopotential for allelectron calculations. Also, Perdew-Wang (PWC/LDA) parametization $^{46}$ was employed for exchange correlation with the same technicalities used in the calculation of $(10,0)$ nanotube. The local-density approximation (LDA) functional depends only on the density at the coordinate where the functional is evaluated wherein the formulae arises from quantum Monte Carlo simulations. Generalized gradient approximations (GGA) on the other hand is still local but it takes into account the gradient of the density at the same coordinate which offers very good results for molecular geometries and ground-state energies. Both GGA and LDA are adapted to estimate the range of the adsorption energy, LDA gives slightly stronger interaction between $\mathrm{H}_{2}$ and TM-doped nanotubes than GGA; conversely, the GGA underestimates the binding energy of $\mathrm{H}_{2}$. The LDA and GGA flavours aide in interpreting if the final binding energies fall within the permissible adsorption energy at room temperature. A triclinic supercell of $30 \times 30 \times$ $12.78 \AA^{3}$ was used to simulate the nanotube with infinite length, with a wall-to-wall distance of at least $10 \AA$, sufficient to avoid in-plane interactions between nanotubes in adjacent unit cells. The lattice parameter c equalled to fivefold of the periodicity of $(10,0)$ SWCNT and the lattice parameters $\mathrm{a}$ and $\mathrm{b}$ were large enough to ignore the effect of neighbouring tubes. The Monkhorst-Pack scheme ${ }^{47}$ was used in the Brillouin zone with $1 \times 1 \times 5$ special k-points for all geometry optimizations with the Broyden-Fletcher-Goldfarb-Shanno (BFGS) algorithm with convergence criterion of $0.005 \AA$ on displacement, and $10^{-5}$ a.u. on the total energy and electron density. The Fermi levels of the spin-unrestricted band structures of $(10,0)$ nanotubes were reset at the $0 \mathrm{eV}$ position. The $4 \mathrm{ND}-\mathrm{CN}_{\mathrm{x}} \mathrm{NT}$ was constructed as shown in figure 1a by deleting 2 carbon atoms and replacing the surrounding $4 \mathrm{C}$ with $4 \mathrm{~N}$. TM was then attached to each of the $4 \mathrm{~N}$ atoms of the $4 \mathrm{ND}-\mathrm{CN}_{\mathrm{x}} \mathrm{NT}$ as presented in figure $1 \mathrm{~b}$.

\section{Results and Discussion}

Figure 1(a) shows the nitrogen-containing $(10,0)$ carbon nanotubes formed by $\mathrm{C}_{114} \mathrm{~N}_{4}$ units $7.83 \AA$ in diameter and $12.78 \AA$ in length. The interlayer bond lengths calculated by density-functional theory for, $\mathrm{C}-\mathrm{C}$ and $\mathrm{C}-\mathrm{N}$ bonds are $\sim 1.425-1.429 \AA$ and $\sim 1.338-1.352 \AA$, respectively. A typical $\left(\mathrm{sp}^{3}\right) \mathrm{C}-\mathrm{C}\left(\mathrm{sp}^{3}\right)$ bond length is $1.54 \AA$. The $\mathrm{C}-\mathrm{N}$ bond length for amines is $1.479 \AA$. Due to the two missing $\mathrm{C}$ atom, the $\mathrm{C}-\mathrm{N}$ bond lengths of porphyrin-like doping are smaller. To analyze the bond lengths and bond angles, all nanotube geometries were optimized at the same level of theory, including porphyrin as a reference. Formation energies of the nitrogen-containing carbon nanotubes with pyridinelike and porphyrin-like vacancy were calculated for a $(10,0)$ nitrogen-doped CNT. The formation energy of porphyrin-like vacancy is $3.10 \mathrm{eV}$ while the pyridinelike vacancy is around $3.17 \mathrm{eV}$. The formation-energy values have a close relationship to the nanotube structures in this study. These indicate that formation of a divacancy is preferred over monovacancy and the dangling bonded carbon atoms near the divacancies would be replaced with four nitrogens from $\mathrm{N}_{2}$ molecules in 


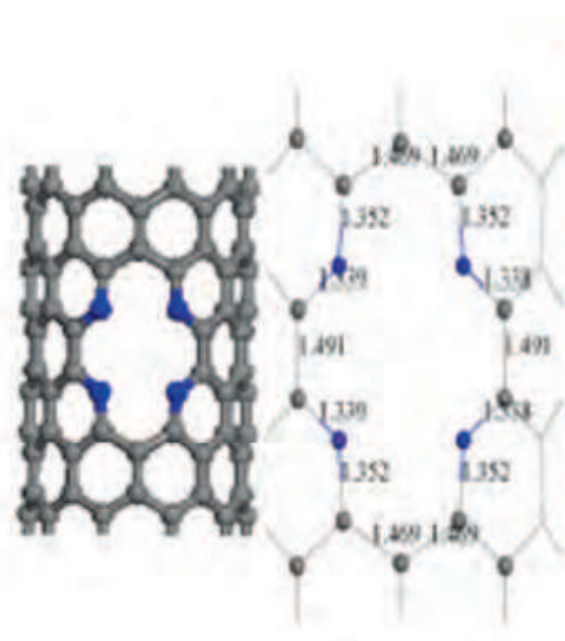

(a) $4 \mathrm{ND}-\mathrm{CN}_{3} \mathrm{NT}$

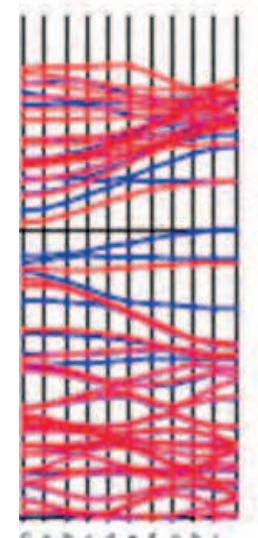

(d) V/4ND

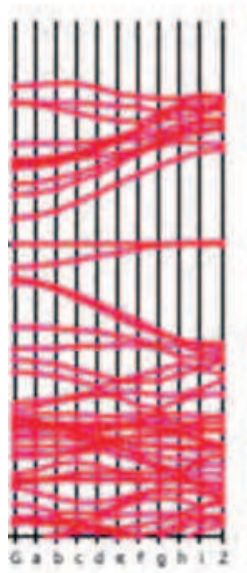

(i) Cu/4ND

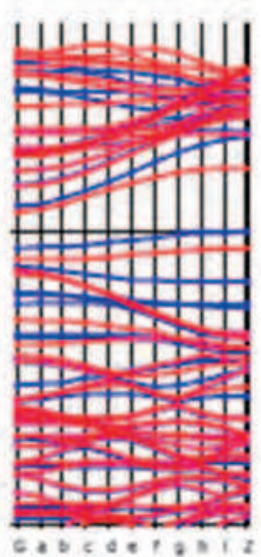

(e) $\mathrm{Cr} / 4 \mathrm{ND}$

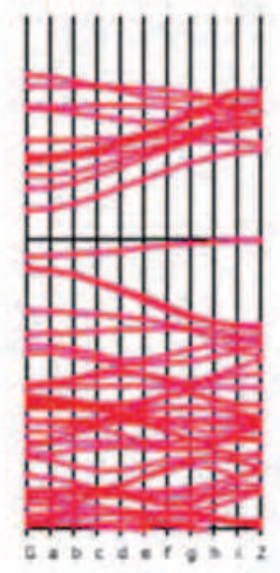

(k) $\mathrm{Zn} / 4 \mathrm{ND}$
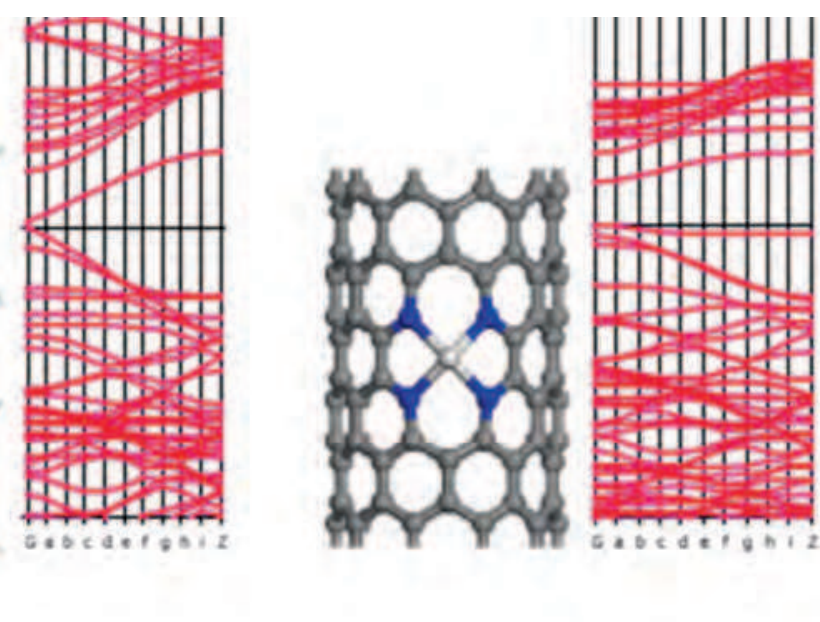

(b) SO4ND

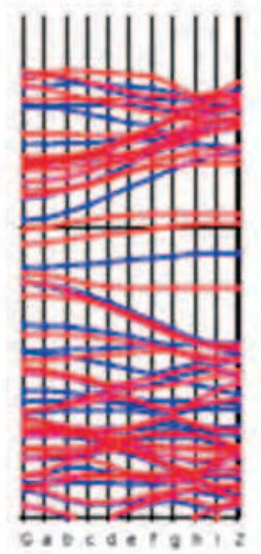

(f) $M / 4 N D$

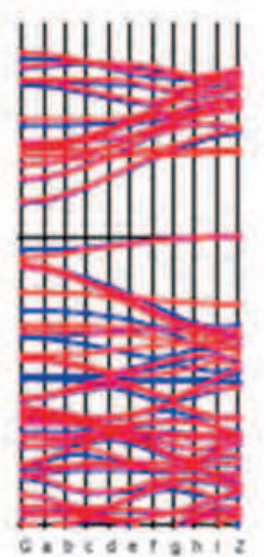

(g) Fo/4ND

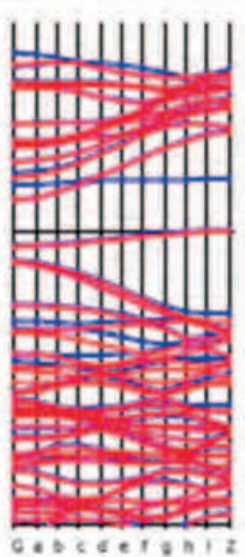

(h) Co/4ND

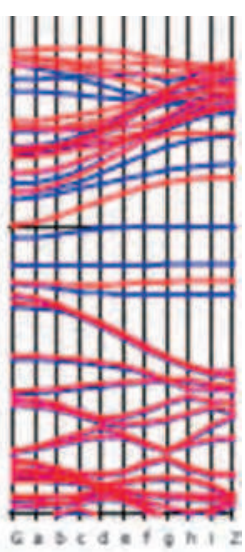

(c) TV/4ND

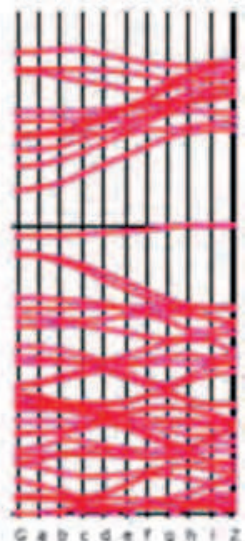

(i) $\mathrm{N} y \mathrm{ND}$

Figure 1. (a) Geometrically optimized structure and bond lengths $(\AA)$ of $\mathrm{N}$ substitution into the carbon framework with the formation of porphyrin-like vacancy. A fragment of the supercell was taken out to elucidate the bond lengths at the vicinity of the N/TM impurities and (b) to (k) band structures of $10 \mathrm{TMs}$ adsorbed on $(10,0)$ zigzag $\mathrm{CN}_{\mathrm{x}} \mathrm{NT}$ with porphyrin-like defect. The Fermi level is set as zero and plotted with a broken line. The blue and red plots denote alpha and beta band structures, respectively. Only one part indicates that this system is non-magnetic. Energies at the vertical axis are at arbitrary units. 
the gas phase in the presence of catalysts or iron oxides. Hirshfeld population analysis shows that charge is of the order $0.116 \mathrm{e}$ on each of the four nitrogen atoms of 4ND-CN ${ }_{x}$ NT. Hence, this site of the nanotube is very reactive as it can act as a strong oxidizing agent for transition metal atoms.

As TM atom is adsorbed on the $\mathrm{CN}_{\mathrm{x}} \mathrm{NT}$, two kinds of initial configurations were considered: (1) the TM is directly bound to the site of $4 \mathrm{ND}$; (2) the TM is attached to the sites near 4ND. After full structural optimization, the TM adsorptions on the defect sites are the most stable because of their higher reactivity than other sites. ${ }^{16,20,21,38-43}$ Based on the comparison of the bond angles and bond lengths of porphyrin, the structure with porphyrin-like defect functionalized with TM can be observed as shown in figure $1 \mathrm{~b}$ for Sc has an increase in the $\mathrm{C}-\mathrm{N}$ bond lengths of nanotube which is $\sim 1.384-1.400 \AA$ although it has a smaller bond lengths than amine. Impurities in CNTs produce their own local strains as expected for these structures as shown in table 1; the structural parameters of most stable configurations of TMs adsorbed on 4ND-CN ${ }_{x}$ NT (labelled as $\mathrm{TM} / 4 \mathrm{ND}-\mathrm{CN}_{\mathrm{x}} \mathrm{NT}$ ) is characterized by forming multiple $\mathrm{TM}-\mathrm{N}$ bonds at the hollow sites wherein all the TMs are projecting from the sidewall of the $4 \mathrm{ND}-\mathrm{CN}_{\mathrm{x}} \mathrm{NT}$ in various ways. The average $\mathrm{TM}-\mathrm{N}$ distances $\left(\mathrm{D}_{\mathrm{TM}-\mathrm{N}}\right)$ of $\mathrm{TM} / 4 \mathrm{ND}-\mathrm{CN}_{\mathrm{x}} \mathrm{NT}$ range from GGA-1.923 (Ni) to 2.144 (Sc) $\AA$ and LDA-1.918 (Ni) to 2.120 (Sc) $\AA$. Thus it can be surmised that $\mathrm{N}$ and TM impurities in CNT produce respective deformations. The binding energy $\left(\mathrm{E}_{\mathrm{b}}\right)$ of an individual TM on the $4 \mathrm{ND}-\mathrm{CN}_{\mathrm{x}} \mathrm{NT}$ is defined as:

$$
\begin{gathered}
\mathrm{E}_{\mathrm{b}}=\mathrm{E}\left(4 \mathrm{ND}-\mathrm{CN}_{\mathrm{x}} \mathrm{NT}\right)+\mathrm{E}(\mathrm{TM})-\mathrm{E}(\mathrm{TM} / 4 \mathrm{ND} \\
\left.-\mathrm{CN}_{\mathrm{x}} \mathrm{NT}\right),
\end{gathered}
$$

where E denotes the total energy of the optimized system the bracket. In table $1, \mathrm{E}_{\mathrm{b}}>0$ for all indicates a stable optimized configuration and bonding. On the other hand, due to the $\mathrm{N}$ participation and the vacancy defect, the binding energies of all TMs on the 4ND$\mathrm{CN}_{\mathrm{x}} \mathrm{NTs}$ are generally larger than those on the pure $\mathrm{CNT}^{48-53}$ such that the presence of porphyrin-like nitrogen defects is crucial for enhancing the metal binding to the defects. The $\mathrm{CN}_{\mathrm{x}} \mathrm{NT}$ with $4 \mathrm{ND}$ defects uses two valence electrons to form a lone pair wherein strong interaction exists between $\mathrm{p}$ orbitals of $\mathrm{N}$ atoms and the $\mathrm{d}$ orbitals of various TMs due to their hybridization with each other.

Table 1. Average TM-N distances $\left(\mathrm{D}_{\mathrm{TM}-\mathrm{N}}\right)$ of $\mathrm{TM} / 4 \mathrm{ND}-\mathrm{CN}_{\mathrm{x}} \mathrm{NT}$, binding energy $\left(\mathrm{E}_{\mathrm{b}}\right)$ of an individual $\mathrm{TM}$ on the 4ND-CN $\mathrm{C}_{\mathrm{x}} \mathrm{NT}$, calculated charge transfer using Hirshfeld population analysis, the charges transferred from TMs to the $(10,0) \mathrm{CN}_{\mathrm{x}} \mathrm{NT}$ with $4 \mathrm{ND}$ defect $\left(\mathrm{C}_{\mathrm{TM}}\right)$, and total magnetic moment $\left(\mu_{\text {total }} \mathrm{TM}\right)$. Average distance between the TM and $\mathrm{H}_{2}\left(\boldsymbol{D}_{\mathbf{T M}-\mathbf{H}}\right)$, average adsorption energies per $\mathrm{H}_{2}$ on TM-decorated $\mathrm{CN}_{\mathrm{x}}$ nanotube with porphyrine-like defects, charge transferred from TMs to the $(10,0) \mathrm{CN}_{\mathrm{x}} \mathrm{NT}$ in the presence of $\mathrm{H}_{2}\left(\mathbf{C}_{\mathbf{T M}-\mathbf{H} 2}\right)$, total magnetic moment $\left(\mu_{\text {total TM-H2 }}\right)$ in the presence of $\mathrm{H}_{2}, \mathrm{H}-\mathrm{H}$ distances $\left(\boldsymbol{D}_{\mathbf{H} 2}\right)$, and charge transferred from from $\mathrm{H}_{2}$ to TM atom $\left(\mathbf{C}_{\mathrm{H} 2}\right)$ using GGA (top) and LDA

\begin{tabular}{|c|c|c|c|c|c|c|c|c|c|c|c|}
\hline$T M$ & $\begin{array}{c}D_{\mathrm{TM}-\mathrm{N}} \\
(\AA)\end{array}$ & $\begin{array}{c}\mathbf{E}_{\mathbf{b}-\mathrm{TM}} \\
(\mathbf{e V})\end{array}$ & $\begin{array}{c}\mathbf{C}_{\mathrm{TM}} \\
\text { (e) }\end{array}$ & $\mu_{\text {total } \mathbf{T M}}$ & $\begin{array}{c}D_{\mathrm{TM}-\mathrm{H} 2} \\
\text { (§) }\end{array}$ & $\begin{array}{c}\mathbf{E}_{\mathrm{b}-\mathrm{H} 2} \\
(\mathrm{eV})\end{array}$ & $\begin{array}{c}\mathbf{G}_{\mathrm{b}-\mathrm{H} 2} \\
(\mathrm{eV})\end{array}$ & $\begin{array}{c}\mathrm{C}_{\mathrm{TM}-\mathrm{H} 2} \\
\text { (e) }\end{array}$ & $\mu_{\text {total } T M-H 2}$ & $\begin{array}{r}D_{\mathrm{H} 2} \\
(\AA)\end{array}$ & $\begin{array}{c}\mathbf{C}_{\mathrm{H} 2} \\
\text { (e) }\end{array}$ \\
\hline $\mathrm{Sc}$ & 2.144 & 8.765 & 0.704 & 0 & 2.324 & 0.239 & 0.302 & 0.573 & 0 & 0.766 & 0.059 \\
\hline $\mathrm{Ti}$ & 2.075 & 8.256 & 0.517 & 1.516 & 1.921 & 0.536 & 0.649 & 0.418 & 0 & 0.828 & 0.022 \\
\hline V & 2.059 & 7.801 & 0.381 & 2.470 & 1.954 & 0.228 & 0.269 & 0.290 & 2.364 & 0.786 & 0.047 \\
\hline $\mathrm{Cr}$ & 2.054 & 5.945 & 0.470 & 0.948 & 1.866 & 0.238 & 0.355 & 0.430 & 0 & 0.808 & 0.012 \\
\hline $\mathrm{Mn}$ & 1.991 & 6.353 & 0.294 & 2.915 & 2.179 & 0.105 & 0.128 & 0.243 & 0 & 0.764 & 0.034 \\
\hline $\mathrm{Fe}$ & 1.967 & 7.397 & 0.231 & 1.911 & 1.630 & 0.311 & 0.376 & 0.142 & 0 & 0.837 & 0.044 \\
\hline Co & 1.950 & 7.598 & 0.195 & 0.9694 & 1.885 & 0.198 & 0.244 & 0.150 & 0.917 & 0.778 & 0.037 \\
\hline $\mathrm{Ni}$ & 1.923 & 7.089 & 0.127 & 0 & 3.143 & 0.013 & 0.091 & 0.131 & 0 & 0.750 & 0.004 \\
\hline $\mathrm{Cu}$ & 2.030 & 4.607 & 0.360 & 0 & 2.075 & 0.067 & 0.346 & 0.346 & 0 & 0.764 & 0.046 \\
\hline $\mathrm{Zn}$ & 2.056 & 3.495 & 0.472 & 0 & 2.212 & 0.119 & 0.118 & 0.442 & 0 & 0.759 & 0.037 \\
\hline $\mathrm{Sc}$ & 2.120 & 10.437 & 0.680 & 0 & 2.199 & 0.408 & 0.425 & 0.515 & 0 & 0.788 & 0.060 \\
\hline $\mathrm{Ti}$ & 2.044 & 10.052 & 0.496 & 1.545 & 1.761 & 0.869 & 1.016 & 0.380 & 0 & 0.865 & 0.018 \\
\hline V & 2.046 & 8.515 & 0.341 & 2.755 & 1.725 & 0.809 & 0.846 & 0.278 & 0.018 & 0.890 & 0.010 \\
\hline $\mathrm{Cr}$ & 2.019 & 7.876 & 0.433 & 0.964 & 1.704 & 0.970 & 1.326 & 0.405 & 0.047 & 0.866 & 0.013 \\
\hline $\mathrm{Mn}$ & 1.968 & 8.387 & 0.254 & 2.983 & 1.958 & 0.589 & 0.723 & 0.114 & 0.004 & 0.873 & 0.022 \\
\hline $\mathrm{Fe}$ & 1.941 & 9.463 & 0.196 & 1.954 & 1.584 & 1.058 & 1.212 & 0.116 & 0 & 0.872 & 0.042 \\
\hline Co & 1.924 & 9.732 & 0.165 & 0.977 & 1.736 & 0.583 & 0.590 & 0.113 & 0.870 & 0.815 & 0.036 \\
\hline $\mathrm{Ni}$ & 1.918 & 8.607 & 0.104 & 0 & 2.903 & 0.517 & 0.857 & 0.103 & 0 & 0.768 & 0.002 \\
\hline $\mathrm{Cu}$ & 1.991 & 5.712 & 0.349 & 0.002 & 1.849 & 0.255 & 0.436 & 0.322 & 0 & 0.795 & 0.015 \\
\hline $\mathrm{Zn}$ & 2.025 & 4.333 & 0.443 & 0 & 2.012 & 0.333 & 0.430 & 0.403 & 0 & 0.781 & 0.018 \\
\hline
\end{tabular}
(bottom). 


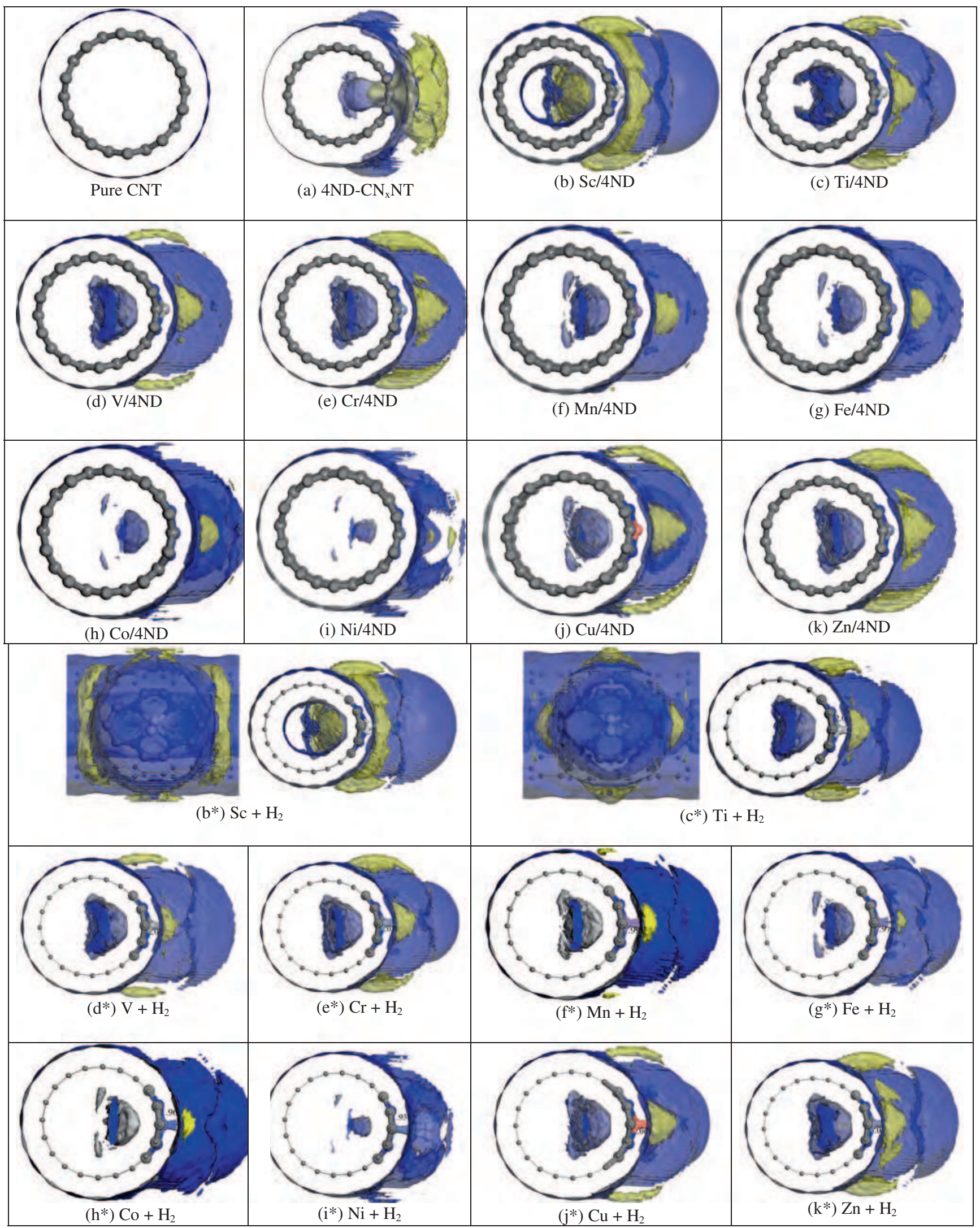

Figure 2. Surface electrostatic potentials of the nitrogen-doped carbon nanotubes functionalized with 3d-block transition metals with and without adsorption of hydrogen using the generalized gradient approximations. 
In figures 1b-1k: the band structures of different $\mathrm{TM} / \mathrm{CN}_{\mathrm{x}} \mathrm{NT}$ nanotubes are represented. It can be seen that upon adsorption of these TMs on $\mathrm{CN}_{\mathrm{x}} \mathrm{NT}$, the electronic properties are changed to different degrees that is strongly dependent on the adsorbed TMs, certain impurity states are introduced into their band structures, rendering the electronic properties to change to different degrees that are strongly dependent on the adsorbed TMs. For example, when $\mathrm{Sc}, \mathrm{Ni}, \mathrm{Cu}, \mathrm{Zn}$ are adsorbed on the two $\mathrm{CN}_{\mathrm{x}} \mathrm{NTs}$, several semiconductors nanocomposites are obtained as their band gaps are increased to different degrees due to the lift of the conduction bands of $\mathrm{CN}_{\mathrm{x}} \mathrm{NTs}$. Interestingly, for Mn adsorptions the influences on electronic properties is completely different: has a half-metallic character. This means that $\mathrm{CN}_{\mathrm{x}} \mathrm{NT}$-based devices with various electronic properties can be achieved. The changes in band structures of the $\mathrm{CN}_{\mathrm{x}} \mathrm{NT}$ upon adsorption of these TMs are also evident by the charge transfer between the TM and the $\mathrm{CN}_{\mathrm{x}} \mathrm{NT}$. As shown in table 1 , in which we list the calculated charge transfer using Hirshfeld population analysis ${ }^{54}$ the charges transferred from TMs to the $(10,0) \mathrm{CN}_{\mathrm{x}} \mathrm{NT}$ with $4 \mathrm{ND}$ defect range from GGA$0.127 \mathrm{e}(\mathrm{Ni})$ to $0.704 \mathrm{e}(\mathrm{Sc})$ and LDA-0.104 e (Ni) to $0.680 \mathrm{e}(\mathrm{Sc})$ which are evident from the surface electrostatic potentials (SEP) shown in figures $2-3$. The delocalized SEP of pure $(10,0)$ nanotube is changed to a polarized form as 4ND defects were introduced shortly after the Sc functionalization, the polarization of the SEP is more enhanced towards the 4ND-Sc dopant indicating partially cationic character of the TMs due to the charge transfer, which facilitates the adsorption of foreign species such as hydrogen gas as discussed next. It is worth noticing that the polarization is weakest at Ni dopant which has a low charge transfer as mentioned before and as observed in both GGA and LDA plots in figure 2-3. When one $\mathrm{H}_{2}$ molecule is adsorbed on the TM/4ND- $\mathrm{CN}_{\mathrm{x}} \mathrm{NT}$ system, the $\mathrm{H}-\mathrm{H}$ bond length is elongated from $0.752 \AA$ of a free $\mathrm{H}_{2}$ to as high as GGA-0.828 $\AA$ (Ti) and LDA-0.890 $\mathrm{\text {(V) }}$ as displayed in table 1 . Optimized $\mathrm{TM}-\mathrm{H}_{2}$ bond length is found to range from GGA-1.630 (Fe) to $3.143(\mathrm{Ni}) \AA$ and LDA-1.584 (Fe) to $2.903(\mathrm{Ni}) \AA$. It is seen in the table depending on the TM incorporated that GGA$0.004 \mathrm{e}(\mathrm{Ni})$ to $0.059 \mathrm{e}(\mathrm{Sc})$ and LDA-0.002e (Ni) to $0.060 \mathrm{e}(\mathrm{Sc})$ charge are transferred from $\mathrm{H}_{2}$ to $\mathrm{TM}$ atom and the entire TM atoms still carry a positive charge $\left(\mathbf{C}_{\mathbf{T M}-\mathbf{H} 2}\right)$, indicating that more $\mathrm{H}_{2}$ molecules can be absorbed as can be visualized in the SEP. Interestingly, Sc posses the maximum electron transferred of about GGA-0.573 e and LDA-0.515e, the average adsorption energies per $\mathrm{H}_{2}$ based on PBE-GGA calculations ranges from 0.013 to $0.536 \mathrm{eV}$ and adsorption energies per $\mathrm{H}_{2}$ based on LDA-PWC ranging from 0.255 to $1.058 \mathrm{eV}$ was obtained and summarized in table 1 . The maximum number of $\mathrm{H}_{2}$ molecules that can be bound to the TM/4ND-CN ${ }_{\mathrm{x}} \mathrm{NT}$ system was calculated using $\mathrm{Sc}$ as the representative to show how much $\mathrm{N}$-doped units can be introduced per unit quantity and how much $\mathrm{H}_{2}$ adsorption can it facilitate. The number of $\mathrm{H}_{2}$ was gradually increased to address the maximum number of $\mathrm{H}_{2}$ molecules that can bound to the Sc/4ND-CN $\mathrm{x}_{\mathrm{x}} \mathrm{NT}$ system and after full relaxation for every $\mathrm{H}_{2}$ adsorption configuration, the GGA predicted that the Sc atom could absorb up to five $\mathrm{H}_{2}$. Correspondingly, based on GGA-PBE calculations the average adsorption energies per $\mathrm{H}_{2}$ ranges from $0.097\left(5 \mathrm{H}_{2}-\mathrm{Sc} / 4 \mathrm{ND}-\mathrm{CN}_{\mathrm{x}} \mathrm{NT}\right)$ to $0.239\left(1 \mathrm{H}_{2}-\mathrm{Sc} / 4 \mathrm{ND}-\mathrm{CN}_{\mathrm{x}} \mathrm{NT}\right) \mathrm{eV}$ in good agreement within the adsorption requirement of hydrogen storage at room temperature of $0.20 \sim 0.70 \mathrm{eV} / \mathrm{H}_{2} .{ }^{55}$ Most importantly, the $\mathrm{H}-\mathrm{H}$ distances are increased slightly from $0.752 \AA$ to $0.758 \AA$ due to the charge transfer from the $\mathrm{H}_{2}$ molecules to the Sc/4ND- $\mathrm{CN}_{\mathrm{x}} \mathrm{NT}$ yet all the adsorbed $\mathrm{H}_{2}$ remain molecular. The adsorption of $\mathrm{H}_{2}$ molecules was studied further on a $5 \mathrm{Sc}$ functionalized to a $\mathrm{CN}_{\mathrm{x}} \mathrm{NT}$ with $54 \mathrm{ND}$ defects. In this case, each $\mathrm{Sc}$ atom carries a positive charge of 0.658 e. Five $\mathrm{H}_{2}$ was placed on each Sc atom. A starting configuration for geometry optimization is taken by attaching $\mathrm{H}_{2}$ as high as 25 around the Sc atoms above the five defects, the hydrogen atoms remain molecular with an average bond length of around $0.755 \AA$ with average hydrogen adsorption energy of $0.092 \mathrm{eV}$ per $\mathrm{H}_{2}$ calculated using GGA-PBE functional the resulting calculation is also verified using LDA as support and it is still in good agreement with the adsorption requirement of hydrogen storage..$^{55}$

On the other hand, free energy values for binding was obtained to serve as a guide to experimentalists are shown in table 1 . The free energy ranges from GGA-0.091 to $0.649 \mathrm{eV}$ and LDA- 0.425 to $1.326 \mathrm{eV}$. Also, the effects of TM adsorption on the magnetic properties of $\mathrm{CN}_{\mathrm{x}} \mathrm{NT}$ is evaluated and found that the net magnetic moment emerges, ranging from GGA2.915, LDA-2.983 (for $\mathrm{Mn} / 4 \mathrm{ND}-\mathrm{CN}_{\mathrm{x}} \mathrm{NT}$ ) to $0 \mu \mathrm{B}$ (for $\mathrm{Sc} /, \mathrm{Ni} /, \mathrm{Cu} /$ and $\mathrm{Zn} / 4 \mathrm{ND}-\mathrm{CN}_{\mathrm{x}} \mathrm{NT}$ ) for the net magnetic moment in the presence of $\mathrm{H}_{2}$, ranges from GGA2.364 (for V/4ND-CN ${ }_{x} \mathrm{NT}$ ), LDA-0.870 (for Co/4ND$\mathrm{CN}_{\mathrm{x}} \mathrm{NT}$ ) to $0 \mu \mathrm{B}$ for the other TMs. This is reasonable, because the ground states of the $\mathrm{CN}_{\mathrm{x}} \mathrm{NTs}$ are non-magnetic, and the net spin magnetic moment mainly originates from the contributions of TMs. The net magnetic moment decreases as the system takes up a $\mathrm{H}_{2}$ wherein a drastic change is experienced in the $\mathrm{Fe}$ case for example where the value drops to zero. 


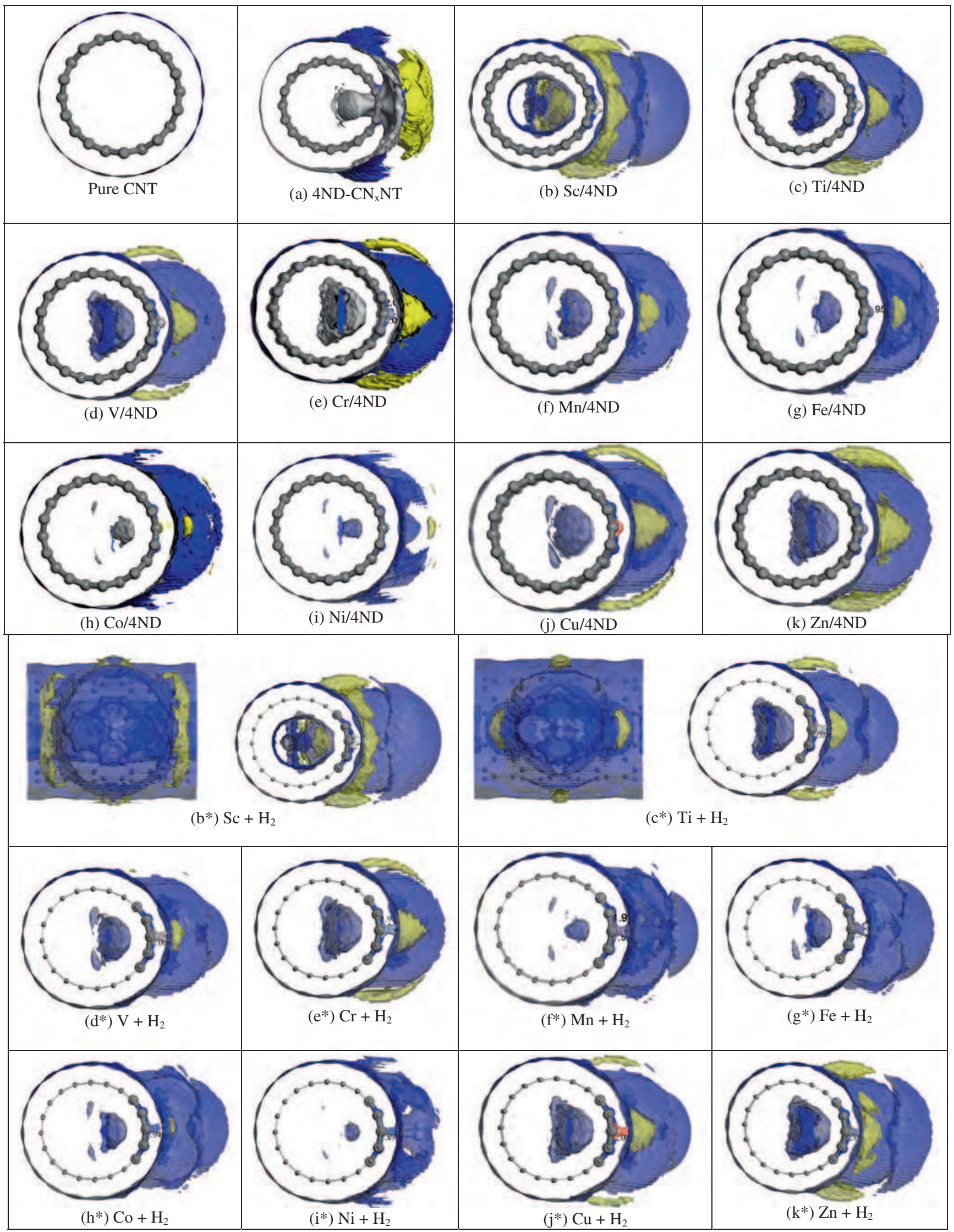

Figure 3. Surface electrostatic potentials of the nitrogen-doped carbon nanotubes functionalized with 3d-block transition metals with and without adsorption of hydrogen using the local-density approximation. 


\section{Conclusions}

The structural, electronic and magnetic properties of the $(10,0)$ nanotube with porphyrin-like nitrogen defects functionalized with $3 \mathrm{~d}$ block TMs ( $\mathrm{Sc}, \mathrm{Ti}, \mathrm{V}, \mathrm{Cr}, \mathrm{Mn}$, $\mathrm{Fe}, \mathrm{Co}, \mathrm{Ni}, \mathrm{Cu}$, and $\mathrm{Zn}$ ) are systemically studied, using density functional theory. Porphyrin defects in SWCNT caused an enhanced transition metal binding and the chemical functionalization of all TMs is thermodynamically stable. The electronic and magnetic properties of TMs on 4ND-CN ${ }_{x} \mathrm{NT}$ can be effectively modified which shows interesting possibilities of tailoring the properties of CNT by TM doping. Binding of hydrogen molecules to the composite material TM/4ND-CN ${ }_{X} \mathrm{NT}$ was observed within the adsorption requirement of hydrogen storage at room temperature suggesting a potential storage media for hydrogen.

\section{References}

1. Tasis D, Tagmatarchis N, Bianco A and Prato M 2006 Chem. Rev. 1061105

2. Zhao Y L and Stoddart J F 2009 Acc. Chem. Res. 42 1161

3. Khabashesku V N, Billups W E and Margrave J L 2002 Acc. Chem. Res. 351087

4. Niyogi S, Hamon M A, Hu H, Zhao B, Bhowmik P, Sen R, Itkis M E and Haddon R C 2002 Acc. Chem. Res. 35 1105

5. Dong L, Craig M M, Khang D and Chen C J 2012 Nanotechnology 20121

6. Mananghaya M, Rodulfo E, Santos G N and Villagracia A R 2012 J. Nanotechnol. 2012780815

7. Sen R, Satishkumar B C, Govindaraj A, Harikumar K R, Renganathan M K and Rao C N R 1997 J. Mater. Chem. 122335

8. Terrones M, Terrones H, Grobert N, Hsu W K, Zhu Y Q, Hare J P, Kroto H W, Walton D R, Ph Kohler-Redlich M W, Rühle M, Zhang J P and Cheetham A K 1999 Appl. Phys. Lett. 753932

9. Czerw R, Terrones M, Charlier J C, Blasé X B, Foley R, Kamalakaran N, Grober H, Terrone D, Tekleab P M, Ajayan W, Blau M and Carrroll D L 2001 Nano. Lett. 1 457

10. Terrones M, Ajayan P M, Banhart F, Blase X, Carroll D L, Charlier J C, Czerw R, Foley B, Grobert N, KohlerRedlich Ph, Rühle M, Seeger T and Terrones H 2002 Appl. Phys. A Mater. Sci. Process 74355

11. Golberg D, Dorozhkin P S, Bando Y, Dong Z C, Tang C C, Uemura Y, Grobert N, Reyes M, Terrones H and Terrones M 2003 Appl. Phys. A Mater. Sci. Process 76 499

12. Villalpando-Páez F, Romero A H, Mnǒz-Sandoval E, Martínez L M, Terrones H and Terrones M 2004 Chem. Phys. Lett. 386137

13. Suenage K, Johansson M P, Hellgren N, Broitman E, Wallenberg L R, Colliex C, Sundgren J and Hultman L 1999 Chem. Phys. Lett. 300695
14. Lim S H, Elim H I, Gao X Y, Wee A T S, Ji W, Lee J Y and Lin J 2006 Phys. Rev. B 73045402

15. Droppa Jr. R, Ribeiro C T M, Zanatta A R, dos Santos M C and Alvarez F 2004 Phys. Rev. B 69045405

16. Villalpando-Paez F, Zamudio A, Elias A L, Son H, Barros E, Chou B S G, Kim Y A, Muramatsu H, Hayashi T, Kong J, Terrones H, Dresselhaus G, Endo M, Terrones M and Dresselhaus M S 2006 Chem. Phys. Lett. 424345

17. Yu S S, Wen Q B, Zheng W T and Jiang Q Nanotechnology 18165702

18. Qiao L, Zheng W T, Xu H, Zhang L and Jiang Q 2007 J. Chem. Phys. 12664702

19. Min Y S, Bae E J, Kim U J, Lee E H, Park N J, Hwang C S and Park W J 2008 Appl. Phys. Lett. 93043113

20. Rocha A R, Rossi M, Fazzio A and da Silva A J R 2008 Phys. Rev. Lett. 100176803

21. Li Y F, Zhou Z and Wang L B 2008 J. Chem. Phys. 129 104703

22. Gong K P, Du F, Xia Z X, Durstock M and Dai L M Science 323760

23. Ayala P, Arenal R, Rümmeli M, Rubio A and Pichler T 2010 Carbon 48575

24. Yoon H, Ko S and Jang J 2007 Chem. Commun. 141468

25. Shao Y, Sui J, Yin G and Gao Y 2008 Appl. Catal. B 78 89

26. Su F B, Tian Z Q, Poh C K, Wang Z, Lim S H, Liu Z L and Lin J Y 2010 Chem. Mater. 27832

27. Li X G, Park S and Popov B N 2010 Power Source 195 445

28. Shao Y Y, Liu J, Wang Y and Lin Y H 2009 J. Mater. Chem. 1946

29. Gregory G, Wildgoose C, Banks E and Richard G C 2006 Small 2182

30. Georgakilas V, Gournis D, Tzizios V, Pasquato L, Guldi D M and Prato M 2007 J. Mater. Chem. 172679

31. White R J, Luque R, Budairn V L, Clark J H and Macquarrie D J 2009 Chem. Soc. Rev. 38481

32. Yue B, Ma Y W, Tao H S, Yu L S, Jian G Q, Wang X Z, Wang X S, Lu Y N and Hu Z 2008 J. Mater. Chem. 18 1747

33. Jiang J S, Ma Y W, Jian G Q, Tao H S, Wang X Z, Fan Y N, Lu Y N, Hu Z and Chen Y 2009 Adv. Mater. 214953

34. Zhou Y, Pasquareli R, Holme T, Berry J, Ginley D and O'Hayre R 2009 J. Mater. Chem. 197830

35. Lepró X, Terrés E, Vega-Cantú Y, Rodríguez-Macías F, Muramatsu H, Kim Y A, Hayahsi T, Endo M, Torres M and Terrones M 2008 Chem. Phys. Lett. 463124

36. Chen Z, Higgins D, Tao H S, Hsu R S and Chen Z W 2009 J. Phys. Chem. C 11321008

37. Sadek A Z, Zhang C, Hu Z, Partridge J G, McCulloch D G, Wlodarski W and Kalantar-zadeh K 2010 J. Phys. Chem. C 114238

38. Yang S H, Shin W H, Lee J W, Kim H S, Kang J K and Kim Y K 2007 Appl. Phys. Lett. 90013103

39. Li Y H, Hung T H and Chen C W 2009 Carbon 47850

40. Feng H, Ma J and Hu Z 2010 J. Mater. Chem. 201702

41. Titov A V, Zapol P, Král P, Liu D J, Iddir H, Baishya K and Curtiss L A 2009 J. Phys. Chem. C 11321629

42. An W and Turner C H 2009 J. Phys. Chem. C 1137069

43. Stoyanov S, Titov A V and Kral P 2009 Coord. Chem. Rev. 2532852

44. Delley B 1990 J. Chem. Phys. 92508 
45. Perdew J P, Burke K and Ernzerhof M 1996 Phys. Rev. Lett. 773865

46. Perdew J P and Wang Y 1992 Phys. Rev. B 45(23) 13244

47. Monkhorst H J and Pack J D 1976 Phys. Rev. B 135188

48. Durgun E, Dag S, Bagci V, Gulseren T and Yildirim C S 2003 Phys. Rev. B 67201401

49. Durgun E, Dag S, Ciraci S and Gulseren O 2004 J. Phys. Chem. B 108575
50. Mananghaya M, Rodulfo E, Santos G N, Villagracia A R and Ladines A N 2012 J. Nanomater. 2012104891

51. Mananghaya M 2014 Bull. Korean Chem. Soc. 35(1) 253

52. Mananghaya M 2012 J. Korean Chem. Soc. 56(1) 34

53. Mananghaya M 2014 J. Chem. Sci. 1261737

54. Hirshfeld F L 1997 Theor. Chim. Acta. 44129

55. Zhao J, Ding Y, Wang X G, Cai Q and Wang X Z 2010 Diamond Related. Mater. 203 